\title{
RESENHA
}

\section{Avaliando a avaliação ${ }^{1}$}

\author{
André Luiz Picolli da Silva \\ Sílvio Paulo Botomé \\ Universidade Federal de Santa Catarina - UFSC
}

\begin{abstract}
Livro: Cruz, R. M.; Alchieri, J. C. \& Sardá Júnior, J. J. (Orgs.) (2002). Avaliação e medidas psicológicas: produção do conhecimento $e \quad d a$ intervenção profissional. São Paulo: Casa do Psicólogo. 277p.
\end{abstract}

Para que avaliar fenômenos psicológicos? No que exatamente pode consistir esse tipo de trabalho? É provável que a maioria dos psicólogos considere necessário e tenha conhecimento de como proceder para realizar uma intervenção na clínica, na escola, em hospitais, no esporte, nas organizações etc. Contudo, será que é possível realizar essa mesma afirmação quando é substituída a palavra intervir pela palavra avaliar? Essa questão merece destaque, pois só é possível realizar uma intervenção eficaz sobre um fenômeno se ele for conhecido, ou seja, se for avaliado. A capacidade de avaliar fenômenos psicológicos, porém, não é "um dom". Ela é construída por meio de trabalho, de estudo e de produção de conhecimento sobre os fenômenos psicológicos e sobre os procedimentos para medi-los, caracterizá-los, compará-los etc. Nesse sentido, o livro "Avaliação e medidas psicológicas" representa uma contribuição para os profissionais e estudantes interessados nos problemas relacionados com a medida e com a avaliação de fenômenos psicológicos. Como avaliar é condição básica para realizar uma intervenção eficaz, as informações apresentadas no livro são importantes para psicólogos, para aqueles que trabalham diretamente com avaliação ou para os que estão em formação, estudando para lidar com esse tipo de fenômeno.

Esses processos, a avaliação e a medida de fenômenos psicológicos, são pouco examinados como problema pelos profissionais e estudantes de psicologia, o que faz com que passem quase desapercebidos nas atividades cotidianas do psicólogo, existindo uma necessidade de estudar e aprofundar o conhecimento crítico sobre esses processos, também eles constituindo fenômenos psicológicos (Botomé \& Rizzon, 1997). Como os autores afirmam, esse é o objetivo da obra, contribuir para o exame da produção do conhecimento e da intervenção profissional em avaliação e medida dos fenômenos e processos psicológicos. As perspectivas de ensino, aprendizagem, capacitação técnica, atuação profissional, pesquisa e publicação são constantemente examinadas ao longo da obra.

Os fenômenos psicológicos ocorrem em toda circunstância onde esteja presente um ser humano (e, muitos outras espécies de seres vivos) e, por conseqüência, suas respectivas avaliações podem ser realizadas nos mais diversos campos de atuação. $\mathrm{O}$ desconhecimento disso faz com que muitos profissionais não percebam muitas das várias possibilidades de atuação existentes no campo da avaliação psicológica. $\mathrm{O}$ exame das várias possibilidades de atuação, nas quais a avaliação psicológica pode ser realizada, bem como amplitude de fenômenos que podem ser avaliados, foi prioridade para os autores. Assim, nos quatorze capítulos que compõem a obra, é examinado como a avaliação psicológica pode ser utilizada nos processos de conhecer, na neuropsicologia, no esporte, no trânsito, no trabalho e nas organizações, no campo jurídico, no diagnóstico do transtorno de déficits de atenção, da dor crônica, do estresse, da carga mental e de crianças vítimas de violência.

É possível que muitos profissionais associem o termo avaliação com "aplicação de testes", exercendo sua atividade de maneira limitada e estereotipada em função dessa compreensão do que seja "avaliação do fenômeno psicológico". No livro "Avaliação e medidas psicológicas" é enfatizada a concepção de que a avaliação e a medida psicológica podem ser mais do que uma atividade de intervenção (ou um campo de atuação), podendo também constituir um objeto de estudo e, com isso, delimitar uma área de conhecimento em Psicologia. Os autores evidenciam que a avaliação psicológica não é só um conjunto de técnicas utilizadas para conhecer um fenômeno específico. Eles acentuam que a avaliação psicológica produz um conhecimento próprio que, além de instrumentalizar uma possível intervenção, serve para realimentar a própria atividade de avaliar. Isso posto, fica aberta a possibilidade e criada a necessidade ou a exigência de que os psicólogos que atuam em relação a esses dois processos ( a avaliação e a medida) tenham a oportunidade de ser, além de avaliador, um produtor de conhecimentos sobre avaliação e medida de fenômenos psicológicos.

Ao estudar a avaliação psicológica, é necessário realizar um exame crítico sobre como está sendo realizada essa atividade pelos psicólogos e quais as consequiências dessa realização para a sociedade. Essa perspectiva é utilizada no texto, refletindo a preocupação dos autores em mesclar o conhecimento 
existente, os procedimentos de intervenção e a ética profissional no trabalho com a medida e com a avaliação dos fenômenos psicológicos.. A ética é evidenciada quando quem atua avalia aquilo que é feito. No caso do livro, quando a avaliação é avaliada. Para que os psicólogos não se transformem em "testólogos" ou "medidores", a avaliação crítica sobre o trabalho de avaliação deve ser constante. Assim como as descobertas feitas nesses processos precisam ser constantemente comunicadas, evitando que a atividade fique estagnada e presa em pequenos mundos de certezas individuais e em reduções do trabalho de psicólogos a "despachantes da Psicologia".

Na busca da prevenção dessa estagnação, o livro surge como um exemplo de movimento. Ỏs trabalhos apresentados são atividades realizadas pelos autores, resultados de pesquisas e de experiências de atuação, concedendo características específicas ao texto. Cada capítulo examina de forma diferente o processo de avaliação, dando uma idéia do dinamismo que constitui a atividade. É importante salientar que, apesar de em alguns capítulos ser demonstrado como proceder para realizar a avaliação dos fenômenos que ocorrem, o livro está longe de ser um simples manual ou guia prático de avaliação psicológica.

A atividade de avaliar não pode existir isoladamente, avaliar por avaliar não faz sentido. Essa atividade como qualquer outra na psicologia, só é pertinente quando acompanhada por outras atividades que, no todo, vão constituir a atuação do profissional. O psicólogo que realiza essa atividade precisa ter os olhos abertos para tudo que diga respeito ao fenômeno avaliado. Um mérito especial que pode ser concedido ao livro, diz respeito ao fato de ele não estar fixado de maneira rígida na questão da avaliação seus capítulos remetem a conceitos, desenvolvimento histórico, estado da arte e contribuições de outras disciplinas. A leitura não fica restrita ao que tradicionalmente é considerado avaliação psicológica, e o leitor, se for leigo em algum dos campos examinados, poderá encontrar um conhecimento a mais sobre os mesmos.

Por fim, o livro é de grande valia para o avanço das discussões sobre a produção do conhecimento, a intervenção profissional e a dimensão ética em avaliação psicológica. Sendo composto pela colaboração de autores que representam diversas instituições de vários pontos do Brasil, é uma obra que fornece uma visão geral de trabalhos que estão sendo realizados no país nessa primeira década do século XXI. É uma leitura fundamental para profissionais e estudantes de Psicologia que trabalham ou pretendam trabalhar com avaliação e com medida de fenômenos psicológicos, e é recomenda para todos os psicólogos na medida em que trata de um processo que se encontra (se não como instrumento, pelo menos como problema) em todo tipo de atuação desse profissional.

\section{REFERÊNCIAS}

Botomé, S. P. \& Rizzon, L. A. (1997). Medidas de desempenho ou avaliação da aprendizagem em um processo de ensino: práticas usuais e possibilidades de renovação. Chronos, 30 (1), 7-34.
Cruz, R. M.; Alchieri, J. C. \& Sardá Júnior, J. J. (2002). Avaliações e Medidas Psicológicas: produção do conhecimento e da intervenção profissional. São Paulo: Casa do Psicólogo. 


\section{Sobre os autores da resenha}

André Luiz Picolli da Silva: Psicólogo; mestrando do Programa de Pós-Gradução em Psicologia da Universidade Federal de Santa Catarina - UFSC. Endereço para correspondência: Rua Barra Velha, 141 Bela Vista I 88110-160 São José - SC - E-mail: kuluzan@hotmail.com.

Sílvio Paulo Botomé: Professor Doutor do Departamento de Psicologia e do Programa de Pós-Gradução em Psicologia da Universidade Federal de Santa Catarina - UFSC - Endereço para correspondência: botome@cfh.ufsc.br. 